\title{
Present and prospective clinical therapeutic regimens for Alzheimer's disease
}

\author{
Mustafa M Husain \\ Kenneth Trevino \\ Haroon Siddique \\ Shawn M McClintock \\ Department of Psychiatry, University \\ of Texas Southwestern Medical \\ Center, Dallas, TX, USA
}

\begin{abstract}
Alzheimer's disease (AD) is an incurable neurodegenerative disorder that produces cognitive impairments that increase in severity as the disease progresses. The clinical symptoms are related to the presence of neuritic plaques and neurofibrillary tangles in the cerebral cortex which represent the pathophysiological hallmarks of AD. The debilitating nature of the disease can result in clinical burden for the patient, emotional strain for those that care for patients with Alzheimer's, and significant financial burden to society. The goals of current treatments, such as cholinesterase inhibitors and N-methyl-D-aspartate receptor antagonist, are to reduce the severity or slow the progression of cognitive symptoms. Although these treatments have demonstrated modest clinical benefit, they are unable to prevent, prohibit, or reverse the underlying pathophysiology of AD. Considerable progress has been made toward the development of disease-modifying treatments. Treatments currently under development mainly target the production, aggregation, and removal of existing amyloid $\beta$-peptide aggregates which are believed to instigate the overall development of the neuropathology. Additional strategies that target tau pathology are being studied to promote neural protection against AD pathology. The current research has continued to expand our knowledge toward the development of disease modifying Alzheimer's therapies; however, no specific treatment strategy capable of demonstrating empirical efficacy and safety has yet to emerge.
\end{abstract}

Keywords: Alzheimer's disease, disease-modifying therapies, current treatments, pathophysiology

\section{Introduction}

Alzheimer's disease (AD) is a progressive neurodegenerative disorder, characterized by a gradual onset and slow progression of cognitive difficulties. The clinical and physiological pathology associated with this illness was first documented by the neuropathologist, Dr. Alois Alzheimer in 1907. AD represents the most common form of dementia syndrome (Fratiglioni et al 2000), which, according to data analyzed from the US Census 2000, affects an estimated 4.5 million people in the Unites States (Hebert et al 2003). The age groups that have the highest number of individuals with a diagnosis of $\mathrm{AD}$ are those 75 to 84 years of age and those 85 or older, with prevalence rates of 2.4 million (53\%) and 1.8 million (40\%), respectively. Because of the estimated increase in people reaching the 75 to 84 and 85 or older age groups, the number of individuals diagnosed with $\mathrm{AD}$ is projected to increase to 13.2 million by the year 2050 .

Caring for patients with AD can create a financial burden to both society and caregivers. The overall cost of AD to the US economy is estimated to be greater than $\$ 141$ billion annually, with an individual patient cost of approximately $\$ 35,000$ per year (Ernst et al 1997). In addition to the monetary cost associated with the illness, caregivers of AD patients also experience significant emotional distress (Donaldson et al 1998; Rymer et al 2002). As the disease progresses and the patient becomes more debilitated, the amount of time spent caring for the patient will also increase, resulting in additional burden on the caregiver. 
The clinical symptoms that are used to diagnose AD manifest gradually, and are difficult to identify in the early stages of the illness. The first symptoms typically reported involve difficulty with memory, such as the inability to recall or learn new information (Greene et al 1996; Salmon et al 2002). Patients may forget appointments and recent conversations, or even get lost while driving (Lipton and Weiner 2003). The memory impairment associated with AD will continue to increase as the illness progresses, eventually affecting well established, crystallized information such as the name of a spouse or children (Yaari and Corey-Bloom 2007). Difficulties with language will also become apparent through word finding and naming difficulties, and a gradual decrease in proper conversations will eventually occur (Vuorinen et al 2000; Blair et al 2007). As with memory and language impairments, executive dysfunction will appear, resulting in a reduction of a patient's ability to complete complex daily activities (Husain and Garrett 2007). This can further increase caregiver burden, as they may be required to take over various responsibilities that were previously handled by the patient. More importantly, the loss of executive functioning also increases the need for continual monitoring and supervision of these patients due to their limited ability to reason, problem solve, and make decisions (Yaari and Corey-Bloom 2007). Eventually, patients with AD will lose the ability or awareness to perform various basic activities associated with daily living such as eating, grooming, or other hygiene related tasks (Galasko et al 2005).

Changes in mood are commonly reported features of $\mathrm{AD}$ and continue throughout the illness course. Mega and colleagues (1996) reported that apathy is the most common psychiatric feature of $\mathrm{AD}(72 \%)$, followed by aggression/agitation (60\%), anxiety (48\%) and depression (48\%). The occurrence of apathy may be related to the decrease in executive function, which may result in an inability to initiate new activities. The more severe behavioral disturbances of psychosis and agitation typically occur in the later stages of the disease and can be difficult to manage.

The neuropathology of AD is characterized by gross brain changes and cortical atrophy that has been found to occur predominantly in the outer three layers of the cerebral cortex, and initially affects the temporal and frontal cortices (Masters et al 2006). The pathological hallmarks of AD are the presence of neuritic plaques and neurofibrillary tangles, which are related to the mass cellular degeneration and neuronal death found in various regions of the brain.

Understanding the process in which neuritic plaques and neurofibrillary tangles form is important when developing effective treatments for $\mathrm{AD}$. Extracellular neuritic plaques present in $\mathrm{AD}$ are an aggregation of amyloid $\beta$-peptides $(\mathrm{A} \beta)$, which consist of 40-42 amino acids (Masters et al 2006). As these extracellular $\mathrm{A} \beta$ peptides or monomers accumulate they form neuritic plaques. The neurotoxicity of these plaques cause damage to the membranes of axons and dendrites, eventually leading to widespread cortical atrophy (Lorenzo et al 2000). This buildup of $A \beta$ has also been suggested to be the main inciting factor for the manifestation and continual progression of $\mathrm{AD}$, as well as the development of the neurofibrillary tangles, which represents the other pathological hallmark of AD (Hardy and Selkoe 2002).

Neurofibrillary tangles are composed of paired helical filaments of abnormally hyperphorylated tau proteins (Masters et al 2006). Within healthy neurons, tau proteins provide structural support for microtubules which are used to send nutrients from the cell body to other regions of the cell. The tau proteins seen in $\mathrm{AD}$ become hyperphosphorylated causing them to aggregate and form tangles within neuronal cells (Lovestone and Reynolds1997). As this occurs, the microtubules are unable to maintain their structure, and thus begin to disintegrate, causing cytoskeletal degeneration which consequently leads to neuronal death. Although other forms of dementia are found to have cortical atrophy or massive neuronal death, the presences of $\beta$-amyloid plaques and neurofibrillary tangles are exclusive pathophysiology of $\mathrm{AD}$, and are believed to accumulate for many years before the onset of memory impairment.

The current method of diagnosing $\mathrm{AD}$ in a clinical setting involves obtaining a detailed clinical history, which is used to determine whether the patient meets certain characteristics of $\mathrm{AD}$ and to rule out other forms of dementia. Criteria from the Diagnostic and Statistical Manual of Mental Disorders, Fourth Edition, Text Revision (DSM-IV-TR APA 2000) and the National Institute of Neurologic, Communicative Disorders and Stroke-AD and Related Disorders Association (NINCDS-ADRDA) (McKhann et al 1984) are the most commonly used diagnostic criteria to define AD. The NINCDS-ADRDA further divides a diagnosis of AD into three distinct categories: definite (clinical diagnosis with histologic confirmation), probable (typical clinical syndrome without histologic confirmation), and possible (atypical clinical features, no alternative diagnosis, no histologic confirmation). Currently, postmortem histological examination of cortical tissue is the only way to establish a definite diagnosis of $\mathrm{AD}$.

The prognosis of $\mathrm{AD}$ is continual neural degeneration with an increase in the range and severity of cognitive 
impairment as the disease progresses (Cummings 2004; Husain and Garrett 2005). A recent study by Larson and colleagues (2004) found that the median survival rate following initial diagnosis of AD was 4.2 years for men and 5.7 years for women. The Alzheimer's patients in this study were found to have a decreased survival rate compared to the life expectancy of the general US population. Although there is currently no cure or method of preventing $\mathrm{AD}$, some limited treatment options are available. The goals of current treatments are to reduce the severity or slow the progression of the cognitive and behavioral symptoms associated with AD (Clark and Karlawish 2003; Farlow 2007). The aim of future treatments under investigation will be to inhibit the progression of the illness or even prevent the onset of $\mathrm{AD}$. This review will describe the safety and efficacy of these current therapeutic treatments and discuss the current state of various disease-modifying treatments.

\section{Current treatments for Alzheimer's disease \\ Cholinesterase inhibitors}

The brains of patients with Alzheimer's have been found to have reduced cholinergic activity (Davies and Maloney et al 1976; Perry et al 1977). It has been suggested that this decrease in cholinergic activity is related to the cognitive symptoms of $\mathrm{AD}$; therefore, enhancing the remaining acetylcholine is believed to improve cognition. The first class of drugs introduced to treat Alzheimer's is referred to as acetylcholinesterase or cholinesterase inhibitors, and are characterized as a symptomatic treatment. Cholinesterase inhibitors are able to prolong the action of the neurotransmitter acetylcholine by reducing its metabolism at the synaptic cleft. The first cholinesterase inhibitor approved by the Food and Drug Administration (FDA) for the treatment of Alzheimer's was tacrine. This treatment was able to slow the progression of cognitive deterioration in $\mathrm{AD}$ patients; however, the clinical significance was not well established (Qizilbash et al 2000). Tacrine is now rarely used because of the increased risk of hepatoxicity, and the development of safer cholinesterase inhibitors. The three commonly used cholinesterase inhibitors, which are approved by the FDA for the treatment of Alzheimer's, include donepezil, galantamine, and rivastigmine. All of these cholinesterase inhibitors have been shown to improve cognition over placebo conditions (Ritchie et al 2004), and they have been found to delay cognitive impairment for up to 6-months in patients with mild to moderately severe AD (Takeda et al 2006).

\section{Donepezil}

Donepezil (Pfizer Inc., NY, USA) is a selective acetylcholine inhibitor which has been shown to reduce the progression of atrophy in the hippocampus (Hashimoto et al 2005), and significantly improve Clinician's Interview Based Impression of Change-plus (CIBIC-plus) scores for patients with moderate to severe $\mathrm{AD}$, relative to placebo (Feldman et al 2005). The CIBIC-plus is a global scale used to assess clinical status that involves a semi-structured interview with the patient and caregiver. Donepezil also demonstrated significant improvement on the Alzheimer's Disease Assessment Scale-Cognition (ADAS-cog) (Birks and Harvey 2006), a scale used to assess cognitive functioning in patients with $\mathrm{AD}$, as well as a delayed decline in the ability of patients with $\mathrm{AD}$ to perform various activities of daily living (ADL). A study by Feldman and colleagues (2003) that provided donepezil daily for 24-weeks to patients with moderate to severe $\mathrm{AD}$ demonstrated a slower decline in instrumental and basic ADLs compared to placebo. The reduction in the decline of patients' ability to perform ADLs was also related to a decrease in stress of the caregivers. Data has indicated patients with mild to moderate AD who delay treatment will not receive full benefit of donepezil, and thus treatment with that medication should be initiated early in the course of AD (Winblad et al 2006).

\section{Rivastigmine}

Rivastigmine (Novartis Pharmaceuticals Corporation, NJ, USA) is a dual acting inhibitor that targets both acetylcholinesterase and butyrylcholinesterase. Treatment with rivastigmine has been shown to provide therapeutic benefit for cognitive symptoms associated with AD. A study by Almkvist and colleagues (2004) compared the cognitive outcome of patients with mild $\mathrm{AD}$ receiving treatment with rivastigmine for 12 months to untreated patients with Alzheimer's or mild cognitive impairment (MCI). The results of the patients with $\mathrm{AD}$ indicated treatment with rivastigmine was able to maintain or minimally improve cognition, compared to a marked decline in cognition for those patients with AD not receiving treatment. Another study, which included patients with moderately severe AD also found rivastigmine to provide symptomatic benefit for cognitive impairment (Burns et al 2004). Patients receiving 6-12 mg/day of rivastigmine for 6 months demonstrated a slight improvement on the ADAS-cog, compared to a decline for patients receiving 
placebo. In addition to providing improvement in cognition, rivastigmine may help improve or prevent psychotic and nonpsychotic symptoms that are associated with Alzheimer's. A review of double-blind randomized trials, which supported the beneficial effect of rivastigmine on cognitive functioning, also demonstrated improvement in activities of daily living (Birks et al 2000). Meta-analytic data, which included three placebo-controlled studies, suggested that treatment with $6-12 \mathrm{mg}$ /day of rivastigmine could potentially reduce or prevent dementia related behavioral and psychological symptoms (Finkel 2004).

\section{Galantamine}

The drug galantamine (Orth-McNeil Neurologics Inc., NJ, USA) is a unique cholinesterase inhibitor that in addition to prolonging the action of the neurotransmitter acetylcholine, is able to allosterically modulate nicotinic acetylcholine receptors which potentate the response of these receptors to acetylcholine (Scott and Goa 2000; Maelicke et al 2001). A 6-month, randomized, controlled trial of galantamine found patients with mild to moderate $\mathrm{AD}$ who received doses of $24 \mathrm{mg} / \mathrm{d}$ or $32 \mathrm{mg} / \mathrm{d}$ had significantly improved cognitive abilities compared to patients who received placebo (Raskind et al 2000). Patients who received active treatment at either dose showed superior scores on both the CIBIC-plus and the 11-item ADAS-cog subscale. Similar results were also indicated in the Cochrane Review (Loy and Schneider 2006), which consisted of ten double-masked, randomized controlled trials. The review concluded that $16 \mathrm{mg} / \mathrm{d}$ to $24 \mathrm{mg} / \mathrm{d}$ of galantamine provided improvement in global and cognitive symptoms for at minimum 6 months. Regarding the long term therapeutic benefit of galantamine, patients that continued to receive $24 \mathrm{mg} / \mathrm{d}$ for an additional 6 months were able to maintain cognitive and daily functioning (Raskind et al 2000). The ability to maintain cognitive functioning was also demonstrated in an observational study that followed patients with mild to moderate $\mathrm{AD}$ who were treated with galantamine for a period of 6-months (Brodaty et al 2006). Although galantamine has a dual mechanism of action, it has not been shown to provide significant benefit over donepezil (Harry and Zakzanis 2005).

\section{Summary of cholinesterase inhibitors}

All three currently approved cholinesterase inhibitors have demonstrated modest symptomatic benefit, and despite variation in their mechanisms of action, there appears to be no difference in their respective efficacy (Birks 2006; Takeda et al 2006). In general, cholinesterase inhibitors are well tolerated; however, various gastrointestinal side effects, such as diarrhea, nausea, and vomiting are common and can reduce treatment compliance. Rivastigmine has a recently FDA-approved skin patch that has been shown to eliminate gastrointestinal side effects (Winblad et al 2007). These drugs should be used judiciously with patients that have cardiac problems, bladder outflow obstruction, seizures, active peptic ulcer disease, or asthma. Refer to Table 1 for additional information concerning each FDA-approved cholinesterase inhibitor. All of these cholinesterase inhibitors have been found to slow the progression of $\mathrm{AD}$, but none have resulted in significant cognitive improvement over a period of time. Also, if these cholinesterase inhibitors are acutely discontinued, there is then a high risk of expedited decline in cognitive functions.

\section{NMDA receptor modulator: Memantine}

Another FDA-approved treatment for AD is memantine (Forest Laboratories Inc., Titusville, NJ, USA) which provides neuroprotection against Alzheimer's pathology. Memantine is an antagonist of the N-methyl-D-aspartate (NMDA) receptor that interferes with glutamate, a neurotransmitter believed to overstimulate the NMDA receptors in AD, causing neuronal death and subsequent cognitive impairment (Lipton and Rosenberg 1994). A randomized, double-masked trial of memantine found that patients with moderate to severe $\mathrm{AD}$ receiving $20 \mathrm{mg}$ /day for 28 weeks had a better outcome relative to patients receiving placebo (Reisberg et al 2003). In addition to the reduction in clinical deterioration which was evident in the CIBIC-plus and ADL Inventory, memantine was well tolerated, as substantiated by a lower discontinuation rate than the placebo group. Another study reported significant reduction in nursing time, extended time to institutionalization, and maintenance of autonomy relative to a placebo condition (Heinen-Kammerer et al 2006). Memantine's therapeutic benefit in cognition and delay in functional decline was also demonstrated in a review of additional randomized controlled studies (McShane et al 2006).

Various randomized controlled trials of memantine have shown less reported agitation in patients with moderate to severe $\mathrm{AD}$ receiving memantine, compared to those receiving a placebo (Reisberg et al 2003; Gauthier et al 2005; van Dyck et al 2007). In regards to safety, a review by Robinson and Keating (2006) indicated the only side effects that occurred at a higher rate over placebo were dizziness, headache, constipation, and somnolence. Memantine has been shown to work in combination with the cholinesterase inhibitor donepezil. This combination resulted in significantly better outcomes on 
Table I Summary of FDA-approved medications for AD

\begin{tabular}{|c|c|c|c|c|}
\hline & Donepezil & Galantamine & Rivastigmine & Memantine \\
\hline Dose & $\begin{array}{l}5 \mathrm{mg} / \mathrm{d} \text { for } 30 \text { days, } \\
\text { then } 10 \mathrm{mg} / \mathrm{d} .\end{array}$ & $\begin{array}{l}4 \mathrm{mg} \text { bid for } 30 \mathrm{~d} \text {, then } \\
16 \mathrm{mg} \text { bid, then } 24 \mathrm{mg} \\
\text { bid. }\end{array}$ & $\begin{array}{l}1.5 \mathrm{mg} \text { bid for } 14 \mathrm{~d} \text {, then } 3 \mathrm{mg} \\
\text { bid for } 14 \mathrm{~d} \text {, then } 4.5 \mathrm{mg} \text { bid } \\
\text { for } 14 \mathrm{~d} \text {, then } 6 \mathrm{mg} \text { bid. }\end{array}$ & $\begin{array}{l}5 \mathrm{mg} / \mathrm{d} \text { for } 7 \mathrm{~d} \text {, then } 5 \mathrm{mg} \\
\text { bid for } 7 \mathrm{~d} \text {, then } 10 \mathrm{mg} \\
\text { in AM } 5 \mathrm{mg} \text { QHS for } 7 \mathrm{~d} \text {, } \\
\text { then } 10 \mathrm{mg} \text { bid. }\end{array}$ \\
\hline Mechanism of action & $\begin{array}{l}\text { Acetyl cholinesterase } \\
\text { inhibitor }\end{array}$ & $\begin{array}{l}\text { Acetyl cholinesterase } \\
\text { inhibitor, also modulates } \\
\text { nicotinic receptors }\end{array}$ & $\begin{array}{l}\text { Acetyl cholinesterase and } \\
\text { butyl cholinesterase inhibitor }\end{array}$ & $\begin{array}{l}N \text {-methyl-D-aspartate } \\
\text { receptor modulator }\end{array}$ \\
\hline Indication & $\begin{array}{l}\text { Mild, moderate, severe } \\
\text { AD }\end{array}$ & Mild-moderate AD & Mild-moderate AD & Moderate-severe AD \\
\hline $\begin{array}{l}\text { Absorption affected } \\
\text { by food }\end{array}$ & No & Yes & Yes & No \\
\hline Protein binding & $96 \%$ & $0 \%-20 \%$ & $40 \%$ & $45 \%$ \\
\hline Common side effects & $\begin{array}{l}\text { Nausea, vomiting, } \\
\text { diarrhea }\end{array}$ & Nausea, vomiting & $\begin{array}{l}\text { Nausea, vomiting, weight loss, } \\
\text { anorexia }\end{array}$ & $\begin{array}{l}\text { Hallucination, confusion, } \\
\text { dizziness, headache }\end{array}$ \\
\hline Serum half life & $70-80$ hrs. & $5-7$ hrs. & 2 hrs. & 45 hrs. \\
\hline Metabolism & CYP2D6, CYP3A4 & CYP2D6, CYP3A4 & Nonhepatic & Nonhepatic \\
\hline Other concerns & $\begin{array}{l}\text { Few drug-drug } \\
\text { interaction }\end{array}$ & $\begin{array}{l}\text { Renal impairment } \\
\text { increases serum level, } \\
\text { paroxetine/ketoconazole } \\
\text { increases serum level }\end{array}$ & $\begin{array}{l}\text { Renal impairment increases } \\
\text { serum level }\end{array}$ & $\begin{array}{l}\text { Alkalinzation of urine to } \\
\mathrm{pH} \text { of } 8 \text { lessens clearance }\end{array}$ \\
\hline
\end{tabular}

Abbreviation: AD, Alzheimer's disease.

various measures over placebo; however, additional research is required to determine the long term benefit of this medication combination (Tariot et al 2004). Refer to Table 1 for additional information regarding memantine.

\section{Non-FDA-approved Alzheimer's disease treatments}

Although donepezil, galantamine, rivastigmine, and memantine are the only FDA-approved treatments for AD, various other agents have been suggested to treat Alzheimer's. Past studies found patients who reported a higher use of nonsteroidal antiinflammatory drugs (NSAIDs) were less likely to develop AD compared to patients with less frequent NSAID use (McGeer et al 1996; Stewart et al 1997). Although these findings suggested that NSAIDs may have neuroprotective properties against the development of $\mathrm{AD}$, recent doublemasked, placebo controlled trials have failed to demonstrate any therapeutic benefit in the development of $\mathrm{AD}$ (Aisen et al 2003; ADAPT Research Group 2007).

The use of estrogen during hormone-replacement therapy (HRT) has also been posited as a neuroprotective treatment for AD. Studies that reviewed the effect of HRT found a decreased risk in the development of dementia (LeBlanc et al 2001; Nelson et al 2002). Although these findings were promising, randomized double-masked, placebo-controlled trials of estrogen failed to find any significant benefit for patients with mild to moderate AD (Henderson et al 2000; Mulnard et al 2000; Wang et al 2000). A study by Shumaker and colleagues (2003) even found postmenopausal women that were treated with estrogen plus progestin had an increased risk for dementia. The use of HRT in women is not currently recommended as a treatment for the maintenance or improvement of cognitive functioning in $\mathrm{AD}$ (Hogervorst et al 2002).

Agents that are able to protect against oxidative damage have been found to serve as a neuroprotective treatment against Alzheimer's. Sano and colleagues (1997) conducted a randomized controlled trial that contrasted the effect of $10 \mathrm{mg} / \mathrm{d}$ of selegiline, $2000 \mathrm{IU} / \mathrm{d}$ of vitamin $\mathrm{E}$, or both selegiline and vitamin $\mathrm{E}$ to a placebo condition in patients with moderate $\mathrm{AD}$. After adjusting for differences in the baseline Mini Mental State Examination (MMSE) scores for the treatment and placebo groups, a significant decrease in the progression of $\mathrm{AD}$ was indicated for those receiving active treatment. There was no statistically significant difference between the three treatment groups. The results from this study did support the use of vitamin $\mathrm{E}$ as a neuroprotective treatment for Alzheimer's; however, not all randomized control trials have been able to demonstrate a benefit. A randomized trial that compared vitamin $\mathrm{E}$ to the cholinesterase inhibitor donepezil in the treatment of patients with $\mathrm{MCI}$ found no benefit for patients receiving vitamin $\mathrm{E}$ (Petersen et al 2005). Patients that received donepezil had a 
decreased rate in the development of Alzheimer's compared to those receiving placebo or vitamin E. Additional research is warranted to determine whether cholinesterase inhibitors and antioxidants, such as vitamin E, provide any significant benefit in the prevention and treatment of $\mathrm{AD}$.

\section{Future disease modifying therapies for Alzheimer's disease}

Unfortunately, the currently approved treatments for AD described above only work to slow the progression of the illness or treat its symptoms. The goals for future disease modifying treatments will include halting the progression of the illness, reversing the physical and cognitive effects associated with the illness, and delaying or even preventing its occurrence. There are certain areas of interest in which various treatment strategies have been developed. The main areas of interest have involved the two pathophysiological hallmarks of $\mathrm{AD}$, which are the neuritic plaques that consist of $A \beta$ proteins and the neurofibillary tangles.

The leading hypothesis indicates that the $A \beta$ peptides are what lead to the overall pathology of AD (Hardy and Selkoe 2002; Klafki et al 2006; Christensen 2007). These peptides are fragments of a transmembrane protein referred to as the amyloid precursor protein (APP) (Bayer et al 2001). During metabolism of this protein, enzymes referred to as $\beta$-secretase and $\gamma$-secretase cleave APP at specific regions, which produce the fragments or monomers that constitute $A \beta$ (Walter et al 2001). The initial cleavage of APP occurs outside the cell by $\beta$-secretase, while $\gamma$-secretase completes the cleavage in the cell membrane (Masters et al 2006). Therefore, the majority of research has focused on decreasing $A \beta$ production, limiting $A \beta$ aggregation, or clearing existing $A \beta$ from the brain. Although less attention has been provided to the neurofibillary tangles, methods for reducing or preventing their development have also been examined.

\section{Treatments based on the $A \beta$ theory}

\section{Removing the existing $A \beta$}

Because the neuritic plaques seen in AD lead to the overall pathology of the disease and accumulate many years before the onset of symptoms, treatments specifically designed to remove existing $A \beta$ plaques or reduce high levels of $A \beta$ peptides are of considerable interest. Increasing the expression of certain $A \beta$ degrading enzymes such as neprilysin (NEP) and insulin-degrading enzyme (IDE), have been suggested as potential methods of reducing the level of existing A $\beta$ levels (Eckman and Eckman 2005). A study using AD transgenic mice that had an over expression of IDE or NEP demonstrated a significant reduction in A $\beta$ levels, which also reduced the development of additional AD pathology (Leissring et al 2003). The authors of this study suggested that reducing the level of $A \beta$ monomers might allow another endogenous mechanism to clear existing plaques. However, a recent study using elderly AD transgenic mice that had already developed plaques found that increased NEP levels did not reduce existing plaques (Mohajeri et al 2004). The use of A $\beta$-degrading enzymes as a treatment for AD will most likely be used in combination with other therapies that can effectively dissolve existing plaque formation.

Another strategy to clear existing $A \beta$ currently in development is immunotherapy with active and passive vaccination against $A \beta$. The use of active immunization for $A \beta$ has been shown to prevent the formation of plaques in young transgenic mice, as well as reduce the progression of $\mathrm{AD}$ like pathology in older mice that had already developed $A \beta$ plaques (Schenk et al 1999). The vaccine AN-1792 reached phase II clinical trials; however, the study was halted after 18 of the $298(6 \%)$ patients that were vaccinated developed meningoencephalitis (Orgogozo et al 2003). Although the study was halted, initial data suggested that the vaccine was effective. Following histology of patients that received AN1792 , significant clearance of $\mathrm{A} \beta$ plaques was discovered (Nicoll et al 2003; Ferrer et al 2004; Masliah et al 2005) and patients that developed $\mathrm{A} \beta$ antibodies demonstrated an improvement in memory and cognition (Gilman et al 2005; Hock et al 2003). These results from AN-1792 were interesting, but due to the risk of developing meningoencephalitis, which may have been related to incidental T-cell activation, the present focus turned to the use of passive immunization.

Passive immunization involves the direct transfer of $\mathrm{A} \beta$ antibodies that can decrease existing plaque formations. Intravenous immunoglobulin preparations (IVIgG) have been found to contain naturally occurring $A \beta$ antibodies which might be able to clear existing A $\beta$ plaques (Du et al 2003). Preliminary data of the efficacy of IVIgG was examined in a small clinical trial that provided treatment (once every four weeks for up to 6 months) to 5 patients with AD (Dodel et al 2004). At completion of the trial, a 30.1\% reduction of $\mathrm{A} \beta$ levels in cerebrospinal fluid was detected with minimal change in performance on cognitive measures. These results indicate the need for a large scale study to adequately determine the clinical benefit of this treatment.

Alternative passive immunizations for $\mathrm{AD}$, such as humanized monoclonal antibodies, include bapineuzumab 
(AAB-001) and LY2062430. A phase II trial of AAB-001 was recently completed, and though results are not expected until late 2008, the manufacturers of the drug have announced they intend to proceed with a phase III clinical trial (Samson 2007). LY2062430 is a version of the m 266 antibody that has been shown to reverse memory deficits in animal models (Dodart et al 2002), and is presently in phase II trials (Eli Lilly, Indianapolis, IN, USA). Passive immunotherapy does represent a safer strategy relative to active immunization. Nonetheless, the exact mechanism of action of $A \beta$ immunotherapy is still unknown, which makes development of any AD immunotherapy difficult.

\section{Limiting the aggregation of $A \beta$}

A review by Walsh and Selkoe (2004) suggested that the accumulation of $A \beta$ is the event that leads to the overall pathophysiology of $\mathrm{AD}$, which is directly related to the memory impairment associated with the disease. After the $\mathrm{A} \beta$ fragments are produced via the cleavage of APP, they begin grouping together, at which point they are believed to produce a neurotoxic effect (Masters et al 2006). Treatments designed to prevent the aggregation of $A \beta$ into plaques are currently being developed. For example, the drug tramiprosate (3-amino-1-propanesulfonic acid) is a compound that has been shown to bind and prevent the aggregation of soluble $A \beta$ in transgenic mice (Gervais et al 2007). According to a recently published report, a phase III clinical trial of tramiprosate in 1052 patients with mild to moderate AD has recently been completed, although the results have yet to be published (Aisen et al 2007).

Iodochlorhydroxyquin (clioquinol) is another drug that has demonstrated antiaggregate properties on $A \beta$. The metal ions copper, zinc, and iron have been found to mediate the aggregation and neurotoxicity of $\mathrm{A} \beta$ (Rogers and Lahiri 2004). Chelating agents like clioquinol binds with zinc and copper ions, and has been found to reduce the accumulation of $A \beta$ in transgenic mice (Cherny et al 2001). A pilot phase II clinical trial of clioquinol demonstrated a decrease in the $A \beta$ levels, compared to an increase found in the placebo group (Ritchie et al 2003). The drug was also well tolerated. It must be noted that the results of this study are limited because of the small sample size, which included 36 patients with AD with 18 receiving active medication and 18 receiving placebo. A drug that has been shown to bind to iron ions is the monoamine oxidase inhibitor M-30. Within a cellular model, this drug has been shown to regulate APP and A $\beta$ levels, thus it may be able to treat various neurodegenerative disorders, including Alzheimer's (Avramovich-Tirosh et al 2007).
NC-531 is a treatment that is currently in phase III clinical trials (Geerts 2004). NC-531 interacts with the metabolism of $A \beta$ and prevents the formation of plaques. In the phase II trial, which included 58 patients with mild $\mathrm{AD}$, there was a $70 \%$ reduction in $\mathrm{A} \beta$ levels. A review of disease modifying Alzheimer's treatments suggest that aggregation inhibitors that are peptide based may be the most effective as they interact with broader regions of the $A \beta$ peptide and have been shown to disaggregate existing $A \beta$ fibrils (Golde 2006).

\section{Decreasing the production of $A \beta$}

Reducing the generation of $A \beta$ through the regulation or modulation of certain secretases responsible for its production represents another novel treatment strategy (Aisen 2005; Hamaguchi et al 2006). $\beta$-secretase inhibitors have been studied as a potential method for the prevention and treatment of AD. Data from animal models have demonstrated that knockout mice lacking the $\beta$-secretase enzyme responsible for the extracellular cleavage of APP have limited A $\beta$ production (Cai et al 2001; Luo et al 2001). Inhibiting $\beta$-secretase is considered a safe treatment strategy; however, additional research is still needed to substantiate that claim. Data from animal studies targeting $\beta$-secretase have demonstrated an increased neonatal mortality rate as well as additional cognitive deficits suggesting this strategy may produce unintended adverse events (Dominguez et al 2005; Laird et al 2005).

The results from a new $\beta$-secretase inhibitor (KMI-429) have been more promising in reducing $A \beta$ production in laboratory and wild type mice, without the development of any apparent adverse events (Asai et al 2006). Although the data from these animal studies have been encouraging, creating an effective $\beta$-secretase inhibitor with good oral bioavailability has proven to be a great challenge. Current compounds that are capable of inhibiting $\beta$-secretase are too large to cross the blood-brain barrier, while smaller compounds that can cross have lacked efficacy (Dewachter and Van Leuven 2002; Citron 2004).

Inhibiting the $\gamma$-secretase, the enzyme responsible for the second cleavage of APP, is another method to reduce the production of $A \beta$. Animal models have demonstrated that $\gamma$-secretase inhibitors are capable of reducing the level of A $\beta$ peptides (Dovey et al 2001; Wong et al 2004; Barten et al 2005). A phase I study of the $\gamma$-secretase inhibitor LY450139 found that participants who were administered $40 \mathrm{mg}$ for 14 days experienced manageable side effects such as headaches, myalgia, and pain, which were also reported in the placebo group (Siemers et al 2005). A reduction in $\mathrm{A} \beta$ concentration was also noted, and was found to be dose 
dependent. Another phase II trial of LY450139 indicated an $\mathrm{A} \beta$ reduction of $58.2 \%$ and $64.6 \%$ for those receiving $100 \mathrm{mg}$ and $140 \mathrm{mg}$ respectively (Eastman 2007). Another $\gamma$-secretase inhibitor that has shown promise is MK-0752 (Rosen et al 2006). A single dose ranging from $110 \mathrm{mg}$ to $1000 \mathrm{mg}$ was well tolerated by 27 healthy participants, and significant reduction in $A \beta$ was observed. Although the data from these initial trials of $\gamma$-secretase inhibitors are promising, these studies had relatively small sample sizes which limited the generalizability of their safety and efficacy. A review by Barten and colleagues (2006) illustrated that $\gamma$-secretase inhibition produced abnormalities in the gastrointestinal tract, thymus, and spleen in animals, which indicates further safety testing is necessary before beginning phase II trials. A feasible substitute to inhibiting the $\gamma$-secretase enzymes may be to modulate its effect on the amyloid precursor protein. Modulation of the $\gamma$-secretase enzyme can also be achieved by the use of NSAIDs, which moves the $\gamma$-secretase cleavage to a shorter $A \beta$ peptide reducing the production of $A \beta 42$ (Eriksen et al 2003). R-Flurbiprofen (Flurizan ${ }^{\mathrm{TM}}$ ) is a NSAID derived modulator that is currently in phase III development (Golde 2006). Results from the phase II trial of Flurizan demonstrated that it was well tolerated and showed significant benefit for patients with mild AD by improving activities of daily living and global function (Black et al 2006).

The $\alpha$-secreatase is another enzyme that cleaves the APP; however, this cleavage occurs between the $A \beta$ sequence which prevents the production of the $A \beta$ fragment responsible for the development of the neurotoxic plaques present in AD (Walter et al 2001; Aisen 2005). Activators of the $\alpha$-secretase can possibly increase this type of passive cleavage of APP and reduce A $\beta$ production. Transgenic mice that have an overexpression of disintegrin and metalloprotease10 (ADAM-10), which activates $\alpha$-secretase, demonstrated a decrease in $A \beta$ peptide production and prevented the formation of amyloid plaques (Postina et al 2004). Although it may be possible to suppress $A \beta$ production by way of inhibition, modulation, or activation of specific protease secretases, data suggests preventing $A \beta$ production would be unable to effectively breakup $A \beta$ that have already aggregated (Jankowsky et al 2005).

Research has also suggested that tumor necrosis factor$\alpha$ (TNF- $\alpha$ ), a proinflammatory cytokine, may play a role in the development of AD by initiating an inflammatory immune response affecting the brain (Perry et al 2001). An open-label, proof of concept study with the TNF- $\alpha$ inhibitor, etanercept, demonstrated improvement on all primary efficacy measures after 6 months of weekly treatment with
25 to $50 \mathrm{mg}$ (Tobinick et al 2006). The data from this study is encouraging; however, large scale, randomized, doublemasked trials are needed.

\section{Treatments based on tau pathology}

\section{Preventing the aggregation of tau}

In addition to the development of treatments that target $A \beta$ aggregation, treatments that are capable of targeting neurofibrillary tangles are also needed to stop the progression of the illness. The majority of treatments that target tau pathology have focused on the hyperphosphorylation and aggregation of tau proteins. The hyperphosphorylation of tau proteins in AD may be related to an enzyme called glycogen synthase kinase $3 \beta$ (GSK-3 $\beta$ ) (Johnson and Hartigan 1999), which can be activated by aggregates of $A \beta$ peptides (Hoshi et al 2003). Recent studies using cell models demonstrated that certain drug inhibitors are able to prevent tau protein aggregation and even dissolve the aggregates that have already developed (Khlistunova et al 2006; Masuda et al 2006). Although these initial findings are promising, in vivo studies are still needed to demonstrate efficacy and safety of tau aggregate inhibitors.

\section{Preventing the phosphorylation of tau}

Preventing the hyperphosphorylation of tau proteins, which is believed to result in tau aggregation, is another strategy under investigation. The phosphorylation of tau is controlled in part by glycogen synthase kinase $3 \beta$ (GSK-3 $\beta$ ), and it has been suggested that inhibiting GSK-3 $\beta$ may prevent the formation of tangles (Bhat et al 2004; Balaraman et al 2006). The M1 muscarinic agonist AF267B (also referred to as NGX267) has been shown to inhibit GSK-3 $\beta$ activity and reduce tau pathology in transgenic mice (Caccamo et al 2006). Lithium has also been suggested as a GSK-3 $\beta$ inhibitor; however, data from a study by Dunn and colleagues (2005) failed to demonstrate a protective response to lithium against the development of AD. Two additional inhibitors of tau hyperphosphorylation that have shown modest success in transgenic mouse models are propentofylline (PPF) and SRN-003-556. Although the exact mechanism of PPF is unknown, it reduced the active form of GSK-3 $\beta$ and prevented the hyperphosphorylation of tau proteins (Chauhan et al 2005). SRN-003-556 was able to reduce soluble tau proteins that were hyperphosphorylated; however, no change was evidenced in existing neurofibrillary tangles (Le Corre et al 2006).

\section{Activating tau chaperones}

In addition to tau aggregation, the misfolding of hyperphosphorylation tau proteins has also been suggested to contribute 
to the intracellular pathology of AD (Golde 2006). Certain proteins are able to regulate and prevent improper folding of tau in order to avoid aggregation. The results from a study by Dou and colleagues (2003) suggested that increasing the activation of molecular chaperones might prevent the misfolding of tau, which would then reduce the development of neurofibrillary tangles. Heat shock proteins have been shown to activate chaperones that prevent misfolding and even promote tau binding with microtubules (Petrucelli et al 2004; Dickey et al 2006). Additional research is required to determine whether targeting tau chaperones would be able to produce significant benefit in humans.

\section{Treatments based on neuroprotection}

Treatment strategies that promote neuronal protection from the pathophysiology associated with Alzheimer's are currently being developed. Increasing the neurotrophic factors, nerve growth factor (NGF) and brain-derived neurotropic factor (BDNF), has been posited to enhance neural survival and improve cognition (Fumagalli et al 2006; Williams et al 2006). The drug AIT-082 (Neotrofin ${ }^{\mathrm{TM}}$ ), a purine derivative that enhances NGF, has been shown to improve working memory in mice (Glasky et al 1994). A phase I trial of AIT082 that included 36 patients with $\mathrm{AD}$, found it to be a safe and well tolerated treatment at doses of $100 \mathrm{mg}, 500 \mathrm{mg}$, and $2000 \mathrm{mg}$ a day (Grundman et al 2003). Neuroprotective agents may be able to help reduce further degeneration, although it is unknown whether this would have a large enough effect on the overall pathology of AD. The glucocorticoid antagonist mifepristone has recently been suggested as a neuroprotective treatment for AD (Dhikav and Anand 2007). Stress has been suggested as a factor that contributes to the development of Alzheimer's (Miller and O'Callaghan 2005); therefore, inhibiting glucocorticoid may help protect against AD-related cellular degeneration. Additional research is needed to determine whether any effect would be clinically significant.

\section{Discussion}

Significant progress has been made in the understanding of the overall course of $\mathrm{AD}$, from the progression of the pathophysiology to the onset of clinical symptoms. This understanding has led to the development of current Alzheimer's treatments which are able to slow the progression of the cognitive symptoms, and modestly control certain behavioral symptoms. These current treatments mainly use symptomatic treatment strategies. Increasing neuroprotection against existing $\mathrm{A} \beta$ plaques and neurofibrillary tangles can help slow the progression of the illness, but current treatments are unable to clear existing or prevent the formation of new $A \beta$ plaques. Another limitation of current treatments involves their inability to reverse existing neuronal damage. The pathology of AD is believed to occur years before the manifestation of clinical symptoms significant enough to indicate a diagnosis of $\mathrm{AD}$; therefore, drugs that are able to reverse the neurodegeneration are warranted. True diseasemodifying therapies are currently being developed to address these limitations.

The goal of future AD treatments will be to inhibit the progression of the illness and reverse its pathology, with the hope of returning cognitive functioning that was previously lost. Because it is currently believed that the pathogenesis of $\mathrm{AD}$ is related to the accumulation of a 40-42-aminoacid referred to as $A \beta$, the majority of treatment strategies have targeted $A \beta$ production and aggregation. Drugs that either inhibit $\beta$-and $\gamma$-secretase or activate $\alpha$-secretase have demonstrated the ability to decrease production (Cai et al 2001; Postina et al 2004; Wong et al 2004; Barten et al 2005; Siemers et al 2005), while other drugs have been able to prevent the aggregation of existing $\mathrm{A} \beta$ peptides (Gervais et al 2007; Cherny et al 2001; Ritchie et al 2003; AvramovichTirosh et al 2007).

Although these strategies are promising, treatments capable of targeting existing $A \beta$ plaques are also in development. Immunotherapy involving active immunization demonstrated initial success in animals (Schenk et al 1999), but due to side effects reported during the phase II trial of AN-1792 (Orgogozo et al 2003), attention has now turned to passive immunization. The passive immunization treatment AAB-001 recently completed a phase II trial, and will soon begin a phase III efficacy trial. The treatment strategies that target tau pathology mainly involve preventing hyperphosphorylation, misfolding, and aggregation of tau proteins. The data from cell and animal models have shown promise in reducing tau pathology (Khlistunova et al 2006; Masuda et al 2006; Balaraman et al 2006; Caccamo et al 2006; Chauhan et al 2005; Dickey et al 2006), but compared to $A \beta$ based treatments, less has been accomplished. If the progression of the illness is caused by the accumulation of $A \beta$, then targeting it could help prevent AD. However, because the neurodegeneration is also related to the neurofibrillary tangles, treatments designed to target tau pathology will be needed.

The difficulty in developing disease-modifying treatments is based on many factors including incomplete understanding of $\mathrm{AD}$ etiology, drug development, adequate trial design, and the associated cost of conducting these trials. Although 
a great deal has been learned regarding the pathology of $\mathrm{AD}$, its etiology remains unclear. Treatments can be developed to target specific stages in the illness, but without a clear understanding of the etiology of $\mathrm{AD}$, it is difficult to know which treatments would have a significant and long lasting effect. Even with the knowledge of what stage in the illness to target, the regular difficulties in drug development are still present. An Alzheimer's drug treatment has to be able to cross the blood brain barrier, perform a specific task, and produce minimal significant side effects which would negate the benefit of the treatment. The demands of conducting an adequate clinical trial for disease-modifying therapies are substantial in terms of duration and cost, which should be at least 18 months or longer (Cummings 2006; Vellas et al 2007) with an estimated cost of $\$ 30$ to 50 million (Melnikova 2007).

Another current limitation is the lack of a biological marker (biomarker) to accurately diagnosis Alzheimer's and to serve as an end-point during trials of disease-modifying treatments. A biomarker is defined as a biological measure that is capable of determining normal or pathogenic processes, as well as a pharmacological response to a treatment intervention (Biomarkers Definitions Working Group 2001). Biomarkers could allow for early treatment intervention and as with most conditions, the sooner therapy is initiated, the better the prognosis. If $\mathrm{AD}$ is unidentified until clinical symptoms are reported, then a significant degree of pathology, which reduces the effectiveness of current treatments, has already developed. In addition to allowing for early initiation of treatment, biomarkers could reduce the number of participants required and strengthen the results of efficacy trials. Because of the extensive range in symptom severity, insidious progression of the disease, and lack of certainty regarding the diagnosis, a large sample size of patients receiving long term treatment and monitoring is required to demonstrate efficacy (Golde 2006). Biomarkers could allow for more accurate enrollment of patients with dementia of the Alzheimer's type and serve as a surrogate end-point to measure the therapeutic benefit of a treatment. Various potential biomarkers such as proteins, genes, and structural changes seen through neuroimaging have shown promise; however, further research is still needed (Vellas et al 2007).

At this time, no treatment is available to halt the progressive neurodegenerative nature of $\mathrm{AD}$. However, as research involving the etiology and pathology of the illness continues, so too will the development of future treatments. Adequate biomarkers have yet to be identified, but their potential worth in clinical application and research trials is significant enough to warrant prospective research regarding their development. Certain treatments have shown promise and through further investigation, their role in combating $\mathrm{AD}$ will become apparent. The development of combination or dual acting treatments, capable of targeting multiple aspects of AD pathology will most likely be needed to significantly alter the progression of the disease.

\section{Conflict of interest}

Dr. Siddique and Mr. Trevino declare that they have no conflict of interest. Dr. McClintock has received research support from the National Institute of Mental Health. Dr. Husain has received research support from the National Institute of Mental Health, Stanley Medical Research Institute, Cyberonics, Inc., Neuronetics, Inc., and Magstim. He has served on Advisory Boards for AstraZeneka, VersusMed, Avinar, Boston Scientific, MEASURE, Bristol-Meyer-Squibb, and Clinical Advisors and on speakers bureaus for Cyberonics, Inc., Avinar, Inc., Cerebrio, Inc., AstraZeneka, Bristol-Meyers-Squibb, Optima/Forrest Pharmaceuticals, Glaxo-Smith-Kline, Forrest Pharmaceuticals, and Janssen.

\section{References}

ADAPT Research Group. 2007. Naproxen and celecoxib do not prevent AD in early results from a randomized controlled trial. Neurology, 68:1800-8.

Aisen P, Gauthier S, Briand R, et al. 2007. A phase III study of the efficacy, safety and disease modification effect of tramiprosate in mild-tomoderate Alzheimer's disease. Alzheimers Dement, 3:197.

Aisen PS, Schafer KA, Grundman M. 2003. Effects of rofecoxib or naproxen vs placebo on Alzheimer disease progression: A randomized controlled trial. JAMA, 289:2819-26.

Aisen PS. 2005. The development of anti-amyloid therapy for Alzheimer's disease from secretase modulators to polymerisation inhibitors. CNS Drugs, 19:989-96.

Almkvist O, Darreh-Shori T, Stefanova E, et al. 2004. Preserved cognition function after 12 months of treatment with rivastigmine in mild Alzheimer's disease in comparison with untreated AD and MCI patients. Eur J Neurol, 11:253-61.

Asai M, Hattori C, Iwata N, et al. 2006. The novel $\beta$-secretase inhibitor KMI-429 reduces amyloid $\beta$ peptide production in amyloid precursor protein transgenic and wild-type mice. J Neurochem, 96:533-40.

Avramovich-Tirosh Y, Amit T, Bar-Am O, et al. 2007. Thereapeutic targets and potential of the novel brain-permeable multifunctional iron chelator-monoamine oxidase inhibitor drug, M-30, for the treatment of Alzheimer's disease. J Neurochem, 100:490-502.

Balaraman Y, Limaye AR, Levey AI, et al. 2006. Glycogen synthase kinase $3 \beta$ and Alzheimer's disease: pathophysiological and therapeutic significance. Cell Mol Life Sci, 63:1226-35.

Barten DM, Guss VL, Corsa JA, et al. 2005. Dynamics of $\beta$-amyloid reductions in brain, cerebrospinal fluid, and plasma of $\beta$-amyloid precursor protein transgenic mice treated with a $\gamma$-secretase inhibitor. J Pharmacol Exp Ther, 312:635-43.

Barten DM, Meredith Jr JE, Zaczek R, et al. 2006. $\gamma$-secretase inhibitors for Alzheimer's disease: Balancing efficacy and toxicity. Drugs $R D$, 7:87-97.

Bayer TA, Wirths O, Majtenyi K, et al. 2001. Key factors in Alzheimer's disease: $\beta$-amyloid precursor protein processing, metabolism and intraneuronal transport. Brain Pathol, 11:1-11. 
Bhat RV, Haeberlein SLB, Avila J. 2004. Glycogen synthase kinase 3: A drug target for CNS therapies. J Neurochem, 89:1313-17.

Biomarkers Definitions Working Group. 2001. Biomarkers and surrogate endpoints: preferred definitions and conceptual framework. Clin Pharmacol Ther, 69:89-95.

Birks J, Grimley EJ, Iakoidou V, et al. 2000. Rivastigmine for Alzheimer's disease. Cochrane Database Syst Rev, 4:CD001191.

Birks J, Harvey RJ. 2006. Donepezil for dementia due to Alzheimer's disease. Cochrane Database Syst Rev, 1:CD001190.

Birks J. 2006. Cholinesterase inhibitors for Alzheimer's disease. Cochrane Database Syst Rev, 1:CD005593.

Black S, Wilcock GK, Haworth J, et al. 2006. Efficacy and safety of MPC7869 (R-Flurbiprofen), a selective Aß42-lowering agent, in mild Alzheimer's disease (AD): Results of a 12-month phase 2 trial and 1-year follow-on study: P06.058. Neurology, 66:A347.

Blair M, Marczinski CA, Davis-Faroque N, et al. 2007. A longitudinal study of language decline in Alzheimer's disease and frontotemporal dementia. JINS, 13:237-45.

Brodaty H, Woddward M, Boundy K, et al. 2006. A naturalistic study of galantamine for Alzheimer's disease. CNS Drugs, 20:935-43.

Burns A, Spiegel R, Quarg P. 2004. Efficacy of rivastigmine in subjects with moderately severe Alzheimer's disease. Int J Geriatr Psychiatry, 19:243-9.

Caccamo A, Salvatore O, Billings LM, et al. 2006. M1 receptors play a role in modulating AD-like pathology in transgenic mice. Neuron, 49:671-82.

Cai H, Wang Y, McCarthy D, et al. 2001. BACE1 is the major $\beta$-secretase for the generation of A $\beta$ peptides by neurons. Nat Neurosci, 4:233-4.

Chauhan NB, Siegel GJ, Feinstein DL. 2005. Propentofylline attenuates tau hyperphosphorylation in Alzheimer's swedish mutant model Tg2576. Neuropharmacology, 48:93-104.

Cherny RA, Atwood CS, Xilinas ME, et al. 2001. Treatment with a copperzinc chelator markedly and rapidly inhibits $\beta$-amyloid accumulation in Alzheimer's disease transgenic mice. Neuron, 30:665-76.

Christensen DD. 2007. Changing the course of Alzheimer's disease: Antiamyloid disease-modifying treatments on the horizon. Prim Care Companion J Clin Psychiatry, 9:32-41.

Citron M. 2004. $\beta$-secretase inhibition for the treatment of Alzheimer's disease - promise and challenge. Trends Pharmacol Sci, 25:92-7.

Clark CM, Karlawish JHT. 2003. Alzheimer disease: Current concepts and emerging diagnostic and therapeutic strategies. Ann Intern Med, 138:400-10.

Cummings JL. 2004. Alzheimer's disease. N Engl J Med, 351: 56-67.

Cummings JL. 2006. Challenges to demonstrating disease-modifying effect in Alzheimer's disease clinical trials. Alzheimers Dement, 2:263-71.

Davies P, Maloney AJF. 1976. Selective loss of central cholinergic neurons in Alzheimer's disease. Lancet, 2:1403.

Dewachter I, Van Leuven F. 2002. Secretases as targets for the treatment of Alzheimer's disease: the prospects. Lancet Neurol, 1:409-16.

Dhikav V, Anand KS. 2007. Glucocorticoids may initiate Alzheimer's disease: A potential therapeutic role for mifepristone (RU-486). Med Hypotheses, 68:1088-92.

Dickey CA, Dummore J, Lu B, et al. 2006. HSP induction mediates selective clearance of tau phosphorylated at proline-directed Ser/Thr sites but not KXGS (MARK) sites. FASEB J, 20:753-5.

Dodart JC, Bales KR, Gannon KS, et al. 2002. Immunization reverses memory deficits without reducing brain $\mathrm{A} \beta$ burden in Alzheimer's disease model. Nat Neurosci, 5:452-7.

Dodel RC, Du Y, Depboylu C, et al. 2004. Intravenous immunoglobulins containing antibodies against $\beta$-amyloid for the treatment of Alzheimer's disease. J Neurol Neurosurg Psychiatry, 75:1472-4.

Dominguez D, Tournoy J, Hartmann D, et al. 2005. Phenotypic and biochemical analyses of BACE1-and BACE2-deficient mice. $J$ Bio Chem, 280:30797-806.

Donaldson C, Tarrier N, Burns A. 1998. Determinants of carer stress in Alzheimer's disease. Int J Geriatr Psychiatry, 13:248-56.
Dou F, Netzer WJ, Tanemura K, et al. 2003. Chaperones increase association of tau protein with microtubules. Proc Natl Acad Sci USA, 100:721-26.

Dovey HF, John V, Anderson JP, et al. 2001. Functional gamma-secretase inhibitors reduce beta-amyloid peptide levels in brain. J Neurochemistry, 76:173-81.

[DSM-IV] Diagnostic and statistical manual of mental disorders. 4th edition. Text revision. 2000. American Psychiatric Association.

Du Y, Wei X, Dodel R, et al. 2003. Human anti-ß-amyloid antibodies block $\beta$-amyloid fibril formation and prevent $\beta$-amyloid-induced neurotoxicity. Brain, 126:1935-9.

Dunn N, Holmes C, Mullee M. 2005. Does lithium therapy protect against the onset of dementia. Alzheimer Dis Assoc Disord, 19:20-2.

Eastman P. 2007. New Alzheimer disease therapies move forward, despite some setbacks. Neurol Today, 7:12.

Eckman EA, Eckman CB. 2005. A $\beta$ - degrading enzymes: Modulators of Alzheimer's disease pathogenesis and targets for therapeutic intervention. Biochem Soc Trans, 33:1101-5.

Eli Lilly. Effects of LY2062430 in subjects with mild-to-moderate Alzheimer's disease and in healthy volunteers [online]. Accessed Dec 12, 2007. URL: http://clinicaltrials.gov.

Eriksen JL, Sagi SA, Smith TE, et al. 2003. NSAIDs and enantiomers of flurbiprofen target $\gamma$-secretase and lower A 342 in vivo. J Clin Invest, 112:440-9.

Ernst RL, Hay JW, Fenn C, et al. 1997. Cognitive function and the costs of Alzheimer disease: An exploratory study. Arch Neurol, 54:687-93.

Farlow MR. 2007. Alzheimer's disease. Continuum, 13:39-68.

Feldman H, Gauthier S, Hecker J, et al. 2003. Efficacy of donepezil on maintenance of activities of daily living in patients with moderate to severe Alzheimer's disease and the effect on caregiver burden: Erratum. J Am Geriatr Soc, 51:1331.

Feldman H, Gauthier, S, Hecker, J, et al. 2005. Efficacy and safety of donepezil in patients with more severe Alzheimer's disease: A subgroup analysis from a randomized, placebo-controlled trial. Int $J$ Geriatr Psychiatry, 20:559-69.

Ferrer I, Rovira MB, Sanchez-Guerra ML, et al. 2004. Neuropathology and pathogenesis of encephalitis following amyloid- $\beta$ immunization in Alzheimer's disease. Brain Pathol, 14:11-20.

Finkel SI, 2004. Effects of rivastigmine on behavioral and psychological symptoms of dementia in Alzheimer's disease. Clin Ther, 26 980-90.

Fratiglioni L, Launer LJ, Andersen K, et al. 2000. Incidence of dementia and major subtypes in Europe: A collaborative study of population-based cohorts. Neurology, 54:10-15.

Fumagalli F, Racagni G, Riva MA. 2006. The expanding role of BDNF: A therapeutic target for Alzheimer's disease. Pharmacogenomics $J$, 6:8-15.

Galasko D, Schmitt F, Thomas R, et al. 2005. Detailed assessment of activities of daily living in moderate to severe Alzheimer's disease. JINS, 11:446-53.

Gauthier S, Wirth Y, Möbius HJ. 2005. Effects of memantine on behavioural symptoms in Alzheimer's disease patients: An analysis of the neuropsychiatric inventory (NPI) data of two randomized, controlled studies. Int J Geriatr Psychiatry, 20:459-64.

Geerts H. 2004. NC-531 neurochem. Curr Opin Investig Drugs, 5:95-100.

Gervais F, Paquette J, Morissette C, et al. 2007. Targeting soluable A $\beta$ peptide with tramiprosate for the treatment of brain amyloidosis. $\mathrm{Neu}$ robiol Aging, 28:537-47.

Gilman S, Koller M, Black RS, et al. 2005. Clinical effects of A $\beta$ immunization (AN1792) in patients with AD in an interrupted trial. Neurology, 64:1553-62.

Glasky AJ, Melchior CL, Pirzadeh B, et al.1994. Effect of AIT-082, a purine analog, on working memory in normal and aged mice. Pharmacol Biochem Behav, 47: 325-9.

Golde TE. 2006. Disease modifying therapy for AD. J Neurochem, 99:689-707 
Greene JDW, Baddeley AD, Hodges JR. 1996. Analysis of the episodic memory deficit in early Alzheimer's disease: Evidence from the doors and people test. Neuropsychologia, 34:537-51.

Grundman M, Capparelli E, Kim HT, et al. 2003. A multicenter, randomized, placebo controlled, multiple-dose, safety and pharmacokinetic study of AIT-082 (Neotrofin ${ }^{\mathrm{TM}}$ ) in mild Alzheimer's disease patients. Life Sci, 73:539-53.

Hamaguchi T, Ono K, Yamada M. 2006. Anti-amyloidogenic therapies: Strategies for prevention and treatment of Alzheimer's disease. Cell Mol Life Sci, 63:1538-52.

Hardy J, Selkoe DJ. 2002. The amyloid hypothesis of Alzheimer's disease: Progress and problems on the road to therapeutics. Science, 297:353-6.

Harry RDJ, Zakzanis KK. 2005. A comparison of donepezil and galantamine in the treatment of cognitive symptoms of Alzheimer's disease: A metaanalysis. Hum Psychopharmacol Clin Exp, 20:183-7.

Hashimoto M, Kazui H, Matsumoto K, et al. 2005. Does donepezil treatment slow the progression of hippocampal atrophy in patients with Alzheimer's disease? Am J Psychiatry, 162:676-82.

Hebert LE, Scherr PA, Bienias JL, et al. 2003. Alzheimer disease in the US population: Prevalence estimates using the 2000 census. Arch Neurol, 60:1119-22.

Heinen-Kammerer T, Rulhoff H, Nelles S, et al. 2006. Added therapeutic value of memantine in the treatment of moderate to severe Alzheimer's disease. Clin Drug Invest, 26:303-14.

Henderson VW, Paganini-Hill A, Miller BL, et al. 2000. Estrogen for Alzheimer's disease in women: Randomized, double-blind, placebocontrolled trial. Neurology, 54:295-301.

Hock C, Konietzko U, Streffer J, et al. 2003. Antibodies against $\beta$-amyloid slow cognitive decline in Alzheimer's disease. Neuron, 38:547-54

Hogersvorst E, Yaffe K, Richards M, et al. 2002. Hormone replacement therapy to maintain cognitive function in women with dementia. Cochrane Database of Sys Rev, 3:CD003799.

Hoshi M, Sato M, Matsumoto S, et al. 2003. Spherical aggregates of $\beta$-amyloid (amylospheroid) show high neurotoxicity and activate tau protein kinase $\mathrm{I} / \mathrm{glycogen}$ synthase kinase-3 $\beta$. PNAS, 100:6370-5.

Husain MM, Garret R. 2007. Differentiating Alzheimer's disease from other dementias and normal aging. Psychiatric Times, 1:23-6.

Husain MM, Garrett R. 2005. Clinical diagnosis and management of Alzheimer's disease. Neuroimag Clin N Am, 15:767-77.

Jankowsky JL, Slunt HH, Gonzales V, et al. 2005. Persistent amyloidosis following suppression of $A \beta$ production in a transgenic model of Alzheimer disease. PloS Med, 2:1318-33.

Johnson GVW, Hartigan JA. 1999. Tau protein in normal and Alzheimer's disease brain: An update. J Alzheimers Dis, 1:329-51.

Khlistunova I, Biernat J, Wang Y, et al. 2006. Inducible expression of tau repeat domain in cell models of tauopathy. $J$ Bio. Chem, 281:1205-14.

Klafki HW, Staufenbiel M, Kornhuber J, et al. 2006. Therapeutic approaches to Alzheimer's disease. Brain, 129:2840-55.

Laird FM, Cai H, Savonenko AV, et al. 2005. BACE1, a major determinant of selective vulnerability of the brain to amyloid- $\beta$ amyloidogenesis, is essential for cognitive, emotional, and synaptic functions. $J$ Neurosci, 25:11693-709.

Larson EB, Shadlen MF, Wang L, et al. 2004. Survival after initial diagnosis of Alzheimer disease. Ann Intern Med, 140:501-9.

LeBlanc ES, Janowsky J, Chan BKS, et al. 2001. Hormone replacement therapy and cognition. JAMA, 285:1489-99.

LeCorre S, Klafki HW, Plesnila N, et al. 2006. An inhibitor of tau hyperphosphorylation prevents severe motor impairments in tau transgenic mice. Proc Natl Acad Sci USA, 103:9673-8.

Leissring MA, Farris W, Chang AY, et al. 2003. Enhanced proteolysis of $\beta$-amyloid in APP transgenic mice prevents plaque formation, secondary pathology, and premature death. Neuron, 40:1087-93.

Lipton AM, Weiner MF. 2003. Differential Diagnosis. In: Frost AG (ed). The Dementias: Diagnosis, Treatment, and Research. Washington, DC: American Psychiatric Publishing, Inc., pp. 137-80.
Lipton SA, Rosenberg PA. 1994. Excitatory amino acids as a final common pathway for neurologic disorders. $N$ Eng J Med, 330:613-22.

Lorenzo A, Yuan M, Zhang Z, et al. 2000. Amyloid $\beta$ interacts with the amyloid precursor protein: A potential toxic mechanism in Alzheimer's disease. Nat Neurosci, 3:460-4.

Lovestone S, Reynolds CH. 1997. The phosphorylation of tau: A critical stage in neurodevelopment and neurodegenerative processes. Neuroscience, 78:309-24.

Loy C, Schneider L. 2006. Galantamine for Alzheimer's disease and mild cognitive impairment. Cochrane Database Syst Rev, 1:CD001747.

Luo Y, Bolon B, Kahn S, et al. 2001. Mice deficient in BACE, the Alzheimer's $\beta$-secretase, have normal phenotype and abolished $\beta$-amyloid generation. Nat Neurosci, 4:231-32.

Maelicke A, Samochocki M, Jostock R, et al. 2001. Allosteric sensitization of nicotinic receptors by galantamine, a new treatment strategy for Alzheimer's disease. Biol Psychiatry, 49:279-88.

Masliah E, Hansen L, Adame A, et al. 2005. A $\beta$ vaccination effects of plaque pathology in the absence of encephalitis in Alzheimer disease. Neurology, 64:129-31.

Masters CL, Cappai R, Barnham KJ, et al. 2006. Molecular mechanisms for Alzheimer's disease: Implications for neuroimaging and therapeutics. J Neurochem, 97:1700-25.

Masuda M, Suzuki N, Taniguchi S, et al. 2006. Small molecule inhibitors of $\alpha$-synuclein filament assembly. Biochemistry, 45:6085-94.

McGeer PL, Schulzer M, McGeer EG. 1996. Arthritis and anti-inflammatory agents as possible protective factors for Alzheimer's disease: A review of 17 epidemiologic studies. Neurology, 47:425-32.

McKhann G, Drachman D, Folstein M, et al. 1984. Clinical diagnosis of Alzheimer's disease. Neurology, 34:939-44.

McShane R, Areosa SA, Minakaran N. 2006. Memantine for dementia. Cochrane Database Syst Rev, 2:CD003154.

Mega MS, Cummings JL, Fiorello T, et al. 1996. The spectrum of behavioral changes in Alzheimer's disease. Neurology, 46:130-35.

Melnikova I. 2007. Therapies for Alzheimer's disease. Nat Rev Drug Discov, 6:341-2.

Miller DB, O'Callaghan JP. 2005. Aging, stress and the hippocampus. Ageing Res Rev, 4:123-40.

Mohajeri MH, Kuehnle K, Li H, et al. 2004. Anti-amyloid activity of neprilysin in plaque-bearing mouse models of Alzheimer's disease. FEBS Lett, 562:16-21.

Mulnard RA, Cotman CW, Kawas C, et al. 2000. Estrogen replacement therapy for treatment of mild to moderate Alzheimer disease: A randomized controlled trial. JAMA, 283:1007-15.

Nelson HD, Humphrey LL, Nygren P, et al. 2002. Postmenopausal hormone replacement therapy. JAMA, 288:872-81.

Nicoll JAR, Wilkinson D, Holmes C, et al. 2003. Neuropathology of human Alzheimer disease after immunization with amyloid- $\beta$ peptide: A case report. Nat Med, 9:448-52.

Orgogozo JM, Gilman S, Dartigues JF, et al. 2003. Subacute meningoencephalitis in a subset of patients with $\mathrm{AD}$ after $\mathrm{A} \beta 42$ immunization. Neurology, 61:46-54.

Perry EK, Perry RH, Blessed G, et al. 1977. Necropsy evidence of central cholinergic deficits in senile dementia. Lancet, 1:189.

Perry RT, Collins JS, Wiener H, et al. 2001. The role of TNF and its receptors in Alzheimer's disease. Neurobiol Aging, 22:873-83.

Petersen RC, Thomas RG, Grundman M, et al. 2005. Vitamin E and donepezil for the treatment of mild cognitive impairment. $N$ Eng $J$ Med, 352:2379-88.

Petrucelli L, Dickson D, Kehoe K, et al. 2004. CHIP and Hsp70 regulate tau ubiquitination, degradation and aggregation. Hum Mol Genet, 13:703-14

Postina R, Schroeder A, Dewachter I, et al. 2004. A disintegrinmetalloproteinase prevents amyloid plaque formation and hippocampal defects in an Alzheimer disease mouse model. J Clin Invest, 113:1456-64.

Qizilbash N, Birks J, López-Arrieta J, et al. 2000. Tacrine for Alzheimer's disease. Cochrane Database Syst Rev, 3:CD000202. 
Raskind MA, Peskind ER, Wessel T, et al. 2000. Galantamine in AD: A 6-month randomized, placebo-controlled trial with a 6-month extension. Neurology, 54:2261-8.

Reisberg B, Doody R, Stoffler A, et al. 2003.Memantine in moderate-tosevere Alzheimer's disease. N Eng J Med, 348:1333-41.

Ritchie CW, Ames D. 2004. Metaanlysis of randomized trials of the efficacy and safety of donepezil, galantamine, and rivastigmine for the treatment of Alzheimer disease. Am J of Geriatr Psychiatry, 12:358-69.

Ritchie CW, Bush AI, Mackinnon A, et al. 2003. Metal-protein attenuation with iodochlorhydroxyquin (clioquiol) targeting $\mathrm{A} \beta$ amyloid deposition and toxicity in Alzheimer disease. Arch Neurol, 60:1685-91.

Robinson DM, Keating GM. 2006. Memantine: A review of its use in Alzheimer's disease. Drugs, 66:1515-34.

Rogers JT, Lahiri DK. 2004. Metal and inflammatory targets for Alzheimer's disease. Curr Drug Targets, 5:535-51.

Rosen LB, Stone JA, Plump A, et al. 2006. The gamma secretase inhibitor MK-0752 acutely and significantly reduces CSF A $\beta 40$ concentrations in humans. Alzheimers Dement, 2:S79.

Rymer S, Salloway S, Norton L, et al. 2002. Impaired awareness, behavior disturbance, and caregiver burden in Alzheimer disease. Alzheimer Dis Assoc Disord, 16:248-53.

Salmon DP, Thomas RG, Pay MM, et al. 2002. Alzheimer's disease can be accurately diagnosed in very mildly impaired individuals. Neurology, 59:1022-8.

Samson K. 2007. 'Passive' Alzheimer vaccine gets accelerated phase 3 start. Neurol Today, 7:15-6.

Sano M, Ernesto C, Thomas RG, et al. 1997. A controlled trial of selegiline, alpha-tocopherol, or both as treatment for Alzheimer's disease. N Eng J Med, 336:1216-22.

Schenk D, Barbour R, Dunn W, et al. 1999. Immunization with amyloid- $\beta$ attenuates Alzheimer-disease-like pathology in the PDAPP mouse. Nature, 400:173-9.

Scott LJ, Goa KL, et al. 2000. Galantamine: a review of its use in Alzheimer's disease. Drugs, 60:1095-22.

Shumaker SA, Legault C, Rapp SR, et al. 2003. Estrogen plus progestin and the incidence of dementia and mild cognitive impairment in postmenopausal women. JAMA, 289:2651-62.

Siemers E, Skinner M, Dean RA, et al. 2005. Safety, tolerability, and changes in amyloid $\beta$ concentrations after administration of a $\gamma$-secretase inhibitor in volunteers. Clin Neuropharmacol, 28:126-32.

Stewart WF, Kawas C, Corrada M, et al. 1997. Risk of Alzheimer's disease and duration of NSAID use. Neurology, 48:626-32.
Takeda A, Loveman E, Clegg A, et al. 2006. A systematic review of the clinical effectiveness of donepezil, rivastigmine and galantamine on cognition, quality of life and adverse events in Alzheimer's disease. Int J Geriatr Psychiatry, 21:17-28.

Tariot PN, Farlow MR, Grossberg GT, et al. 2004. Memantine treatment in patients with moderate to severe Alzheimer disease already receiving donepezil. JAMA, 291:317-24.

Tobinick E, Gross H, Weinberger A, et al. 2006. TNF-alpha modulation for treatment of Alzheimer's disease: A 6-month pilot study. MedGenMed, $8: 25$.

van Dyck CH, Tariot PN, Meyers B, et al. 2007. A 24-week randomized, controlled trial of memantine in patients with moderate-to-severe Alzheimer disease. Alzheimer Dis Assoc Disord, 24:136-43.

Vellas B, Andrieu S, Sampaio C, et al. 2007. Disease-modifying trials in Alzheimer's disease: a European task force consensus. Lancet Neurol, 6:56-62.

Vuorinen E, Laine M, Rinne J. 2000. Common pattern of language impairment in vascular dementia and in Alzheimer disease. Alzheimer Dis Assoc Disord, 14:81-6.

Walsh DM, Selkoe DJ. 2004. Deciphering the molecular basis of memory failure in Alzheimer's disease. Neuron, 44:181-93.

Walter J, Kaether C, Steiner H, et al. 2001. The cell biology of Alzheimer's disease: Uncovering the secrets of secretases. Curr Opin Neurobiol, 11:585-90.

Wang PN, Liao SQ, Liu RS, et al. 2000. Effects of estrogen on cognition, mood, and cerebral blood flow in AD. Neurology, 54:2061-6.

Williams BJ, Eriksdotter-Jonhagen M, Granholm AC. 2006. Nerve growth factor in treatment and pathogenesis of Alzheimer's disease. Prog Neurobiol, 80:114-28.

Winblad B, Cummings J , Andreasen N, et al. 2007. A six-month doubleblind, randomized, placebo-controlled study of a transdermal patch in Alzheimer's disease - rivastigmine patch versus capsule. Int J Geriatr Psychiatry, 22:456-67.

Winblad B, Wimo A, Engedal K, et al. 2006. 3-year study of donepezil therapy in Alzheimer's disease: effects of early and continuous therapy. Dement Geriatr Cogn Disord, 21:353-63.

Wong GT, Manfra D, Poulet FM, et al. 2004. Chronic treatment with the gamma $\gamma$-secretase inhibitor LY-411,575 inhibits $\beta$-amyloid peptide production and alters lymphopoiesis and intestinal cell differentiation. J Biol Chem, 279:12876-82.

Yaari R, Corey-Bloom J. 2007. Alzheimer's disease. Semin Neurol, $27: 32-41$ 
